\title{
Successful removal of an unusual rectal foreign body with a Kocher clamp
}

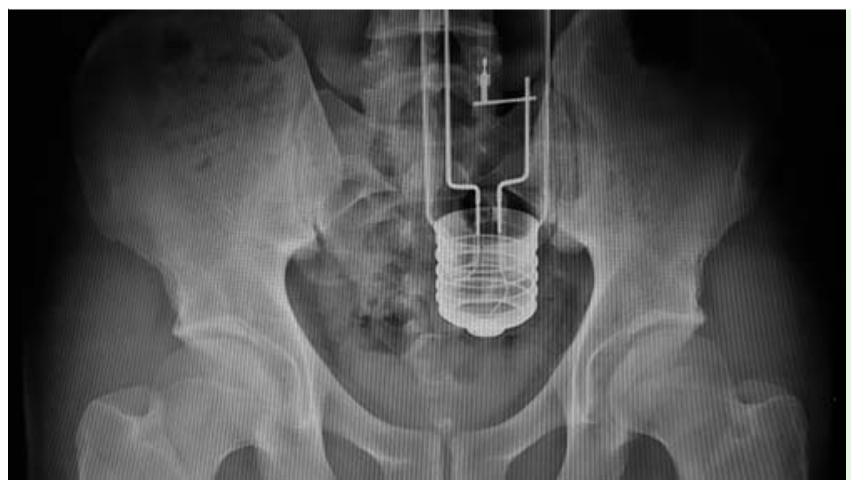

Fig. 1 Pelvic X-ray of the foreign body in the rectum of a 26-year-old man who had reported that he had inserted a large light bulb in his rectum about 3 hours prior to presentation.

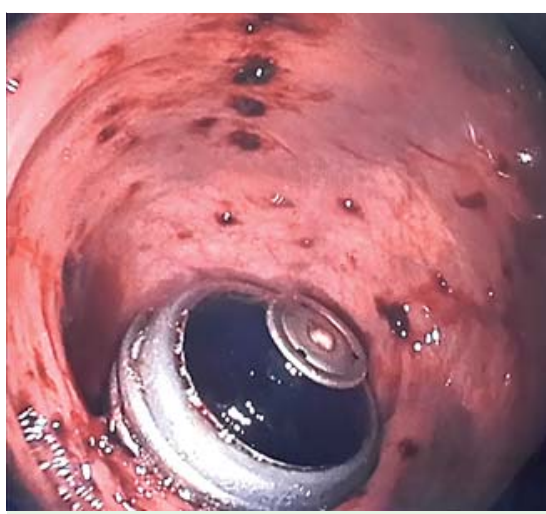

Fig. 2 Endoscopic image of the foreign body in the rectum completely obstructing the lumen.

A 26-year-old man presented at our emergency department with a history of severe pelvic pain and bloating. The patient reported that he had inserted a large light bulb in his rectum about 3 hours prior to presentation. On digital rectal examination, a foreign body with an irregular surface was palpated. An X-ray image of the pelvic region revealed a large light bulb in the rectum ( $\mathbf{\text { Fig. }} \mathbf{1}$ ). Attempted manual removal of the foreign body using suprapubic pressure failed. Colonoscopy revealed that the bulb in the rectum was completely obstructing the lumen ( Fig.2). A polypectomy snare failed to remove it because of the bulb's round, smooth surface. The foreign body was completely removed without complication using a long Kocher clamp under colonoscopic observation and thus avoiding surgery ( Fig.3). Control endoscopy showed only mild superficial scratches on the rectal mucosa.
Foreign bodies have generally been inserted in the rectum for sexual gratification and are usually round and have a smooth surface [1]. It is difficult to remove these foreign bodies with standard endoscopic devices. In such cases, a surgical Kocher clamp can be used in the treatment of large rectal foreign bodies thus avoiding surgery [2].

\section{Endoscopy_UCTN_Code_TTT_1AQ_2AH}

\section{Competing interests: None}

\section{Barış Yılmaz ${ }^{1}$, Serkan Ozmete ${ }^{2}$, Akif Altınbas' ${ }^{1}$ Bora Aktaş ${ }^{1}$, Fuat Ekiz'}

${ }^{1}$ Diskapi Yildirim Beyazit Education and Research Hospital, Gastroenterology, Ankara, Turkey

${ }^{2}$ Osmaniye State Hospital, Surgery, Osmaniye, Turkey

\section{References}

1 Fry RD. Anorectal trauma and foreign bodies. Surg Clin North Am 1994; 74: 1491 1505

2 Kouraklis G, Misiakos E, Dovas N et al. Management of foreign bodies of the rectum: report of 21 cases. J R Coll Surg Edinb 1997; 42: $246-247$

\section{Bibliography}

DOI http://dx.doi.org/

10.1055/s-0034-1377768

Endoscopy 2014; 46: E549

(c) Georg Thieme Verlag KG

Stuttgart · New York

ISSN 0013-726X

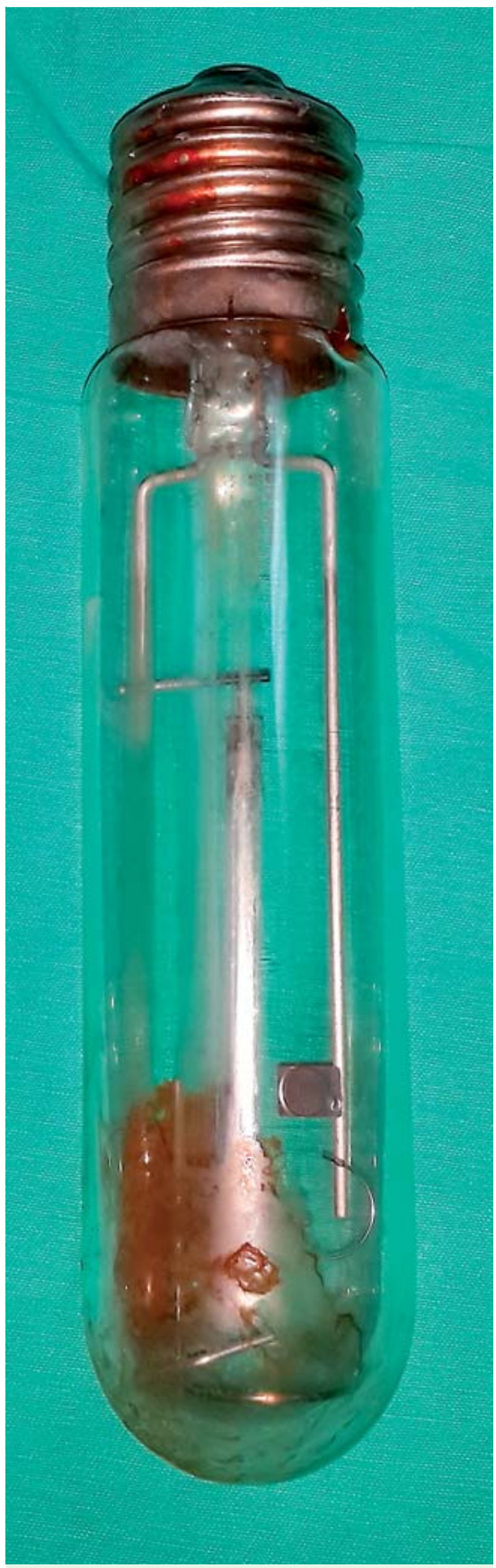

Fig. 3 The extracted rectal foreign body removed without complication.

Corresponding author

\section{Barış Yılmaz, MD}

Camlikevler mahallesi

4. Blok No: 6 Toprakkale

Osmaniye

Turkey

Fax: +90-328-8257072

dryilmazb@gmail.com 